\title{
A prática cartonera, uma expressão do comum
}

\author{
The cartonera practice, an expression of the common
}

\author{
Carolina Noury
}

Prática cartonera, Eloísa Cartonera, Dulcinéia Catadora, comum

O livro cartonero é um artefato de resistência ao modelo colonialista capitalista produzido a partir do papelão, material descartado no lixo e reintegrado no ciclo produtivo por meio do trabalho dos catadores de material reciclado. Neste artigo buscaremos apresentar o contexto político e econômico que propiciou o surgimento da primeira cartonera, Eloísa Cartonera, na Argentina, e a disseminação dessa prática pelo mundo, sobretudo na América Latina, entre elas o coletivo Dulcinéia Catadora. Localizado na cidade de São Paulo, dentro de uma pequena sala de uma cooperativa de catadores de materiais recicláveis, é nesse espaço que o coletivo encontra a força capaz de gerar outros modos de vida. O livro cartonero pode ser compreendido como uma prática revolucionária vinculada à ideia do comum na medida em que rompe com a lógica de produção capitalista neoliberal e coloca o catador e o lixo no centro de sua produção. Uma produção coletiva que privilegia o fazer-comum reunindo uma multiplicidade de atores que valoriza a criação de laços e afetos gerando formas responsivas de conviver mostrando a possibilidade de outras formas de habitar o mundo.

Cartonera practice, Eloísa Cartonera, Dulcinéia Catadora, common

The cartonero book is an artifact of resistance to the colonialist capitalist model produced from cardboard, material discarded in the trash and reintegrated into the production cycle through the work of recycled material collectors. In this article we will seek to present the political and economic context that led to the emergence of the first cartonera, Eloísa Cartonera, in Argentina, and the dissemination of this practice throughout the world, especially in Latin America, including the collective Dulcinéia Catadora. Located in the city of São Paulo, inside a small room of a cooperative of collectors of recyclable material, is in this space that the collective finds the strength capable of generating other ways of life. The cartonero book can be understood as a revolutionary practice linked to the idea of the common insofar as it breaks with the neoliberal capitalist production logic and places the collector and garbage at the center of its production. A collective production that favors commoning, bringing together a multiplicity of actors that values the creation of bonds and affections, generating responsive ways of living, showing the possibility of other ways of inhabiting the world.

\section{Big Bang cartonero}

O final dos anos 1990 foi marcado por uma crise financeira mundial decorrente da crise dos Tigres Asiáticos. Diversos países foram afetados por essa crise, entre eles o Brasil com a crise de desvalorização do real, conhecida como efeito samba, e a Argentina que entra em recessão em 1997. O governo argentino, para atender às exigências do Fundo Monetário Internacional

Anais do $10^{\circ} \mathrm{CIDI}$ e $10^{\circ} \mathrm{CONGIC}$

Kelli C.A.S. Smythe, Rafael de Castro Andrade (orgs.)

Sociedade Brasileira de Design da Informação - SBDI

Curitiba | Brasil | 2021
Proceedings of the $10^{\text {th }} \mathrm{CIDI}$ and $10^{\text {th }}$ CONGIC

Kelli C.A.S. Smythe, Rafael de Castro Andrade (orgs.)

Sociedade Brasileira de Design da Informação - SBDI Curitiba | Brazil | 2021 
(FMI), adota diversas medidas de austeridade, entre elas o aumento dos impostos. Esse período é seguido por uma série de greves gerais e manifestações populares no país hermano.

A crise econômica, política, social e institucional que Buenos Aires enfrentava foi agravada em 2001 quando o país congelou os depósitos a fim de evitar a quebra dos bancos chegando a declarar moratória. As medidas tomadas pelo governo como o "corralito", que buscava evitar a retirada de depósitos em contas correntes e poupança estabelecendo um limite de retirada semanal, causou uma grande insatisfação popular que mobilizou uma série de violentos protestos e manifestações a favor do impeachment.

O espaço urbano foi transformado em espaço de assembleias e manifestações, a população ocupava as ruas batendo suas panelas manifestando sua revolta, protestos que ficaram conhecidos como "panelaço" ou cacerolazo. As revoltas sociais e o conflito violento com a polícia e agentes de segurança deixaram 39 mortos, incluindo sete crianças, e uma centena de feridos, e culminaram por decretar estado de sítio que suspendeu todas as garantias constitucionais dos cidadãos.

As intensas manifestações populares durante o mês de dezembro acabou causando a renúncia do presidente eleito Fernando de la Rúa que deixou a Casa Rosada pelo terraço, de helicóptero, a fim de evitar um confronto com os manifestantes. O país chegou a ter cinco presidentes em um período de apenas doze dias. "QQue se vayan todos!" foi o lema das manifestações populares, desafiando o estado de sítio decretado, que expressavam o descontentamento com seus dirigentes e convocavam toda população para a rua. Segundo Vilhena (2016) essa crise representa o esgotamento da política econômica vigente, o de acumulação capitalista neoliberal.

Esse cenário de crise com elevada taxa de pobreza, trabalho informal e desemprego fez aumentar o número de pessoas que se dedicaram a coletar o lixo urbano no centro da cidade de Buenos Aires, entre papelão (cartón) e outros materiais recicláveis, os cartoneros. Caviasca apud Vilhena (2016) percebeu que "a classe média argentina, por uma urgência do real, precisou abrir mão de alguns valores e práticas, já que se deparou com a necessidade de recorrer a modos de sobrevivência até então não cogitados, como a coleta de materiais descartados que poderiam ser reciclados" (p. 31).

Em geral, os centros de reciclagem de materiais recicláveis ficam localizados na periferia da cidade, enquanto que a maior parte do material recolhido das ruas se concentra no centro. Para isso, era preciso que os catadores se deslocassem do centro para a periferia através da linha ferroviária metropolitana. O Trem Branco ou Trem Cartonero é um serviço que surgiu decorrente dessa crise de 2001 que transportava os cartoneros do centro até as periferias onde se encontravam os centros de reciclagem. Para esse serviço, eram utilizados os trens fora de serviço, em estado de abandono, sem poltronas e sem luz. Esses vagões abandonados foram destinados aos cartoneros e suas cargas de papelão. Desta forma, o Trem Branco retratou a precariedade do trabalho informal dos cartoneros que fornece a matéria-prima para a lucrativa indústria de reciclagem do mercado formal (Vieira \&Thompson, 2012). 
Os cartoneros são trabalhadores que circulam pelas cidades da Argentina ao longo da história, entretanto, ganharam destaque na cena urbana de Buenos Aires a partir dessa crise do início do século XXI, quando novos cartoneros estreantes nesta modalidade de trabalho se juntaram aos catadores tradicionais. Vieira \& Thompson (2012) identificam dois fatores relacionados a essa erupção desses novos atores sociais: a ditadura militar de 1976 que trouxe a prevalência do discurso neoliberal e a radicalização dessas políticas na década de 1990, como a formação de grandes conglomerados e o incentivo às privatizações gerando altas taxas de desemprego. Assim, a década de 1990 representou um acirramento das políticas neoliberais na Argentina que foi marcado pela quebra da indústria nacional aumentando o índice de desemprego no país.

No final da década de 1970, o governo argentino proibiu a queima de lixo e substituiu o método anterior por aterros nas áreas suburbanas de Buenos Aires. Beneficiou tremendamente os grandes setores privados com a proibição de catação, privatização da coleta e criação de um cordão ecológico no subúrbio de Buenos Aires (o chamado Cinturón Ecológico da Área Metropolitana Sociedad del Estado, CEAMSE) para a recuperação de resíduos com base em planejamento técnico. (...) O valor do que antes era descartado como lixo aumentou desde a crise, pois a importação de bens como papel e plástico tornou-se muito cara. Efetuou-se a construção de uma indústria nacional que produza bens acessíveis essenciais à sobrevivência do mercado nacional (CHRONOPOLUS, 2006, p. 168). Nesse contexto, a redução do mercado de trabalho formal sob as políticas neoliberais radicais do governo argentino dos anos 1990 levou a um rápido aumento do número de cartoneros. (Vieira \& Thompson, 2012, pp. 66-67).

Pimentel (2021) destaca que a presença dos cartoneros pode ser entendida como a marca mais visível da crise na Argentina. Longe de uma romantização, a crise fez emergir e fortalecer movimentos coletivos, de solidariedade e organizações de cooperativas de modo que as práticas artísticas se tornaram ainda mais coletivas, realizadas em conjunto a fim de superar a individualidade em prol de uma proposta comum. É nesse contexto que surge a primeira editora cartonera, o coletivo Eloísa Cartonera, "como forma de enfrentar a crise e gerar renda para um grupo de cartoneros" (idem, p. 4).

Com o slogan "muito mais que livros", Eloísa Cartonera mostra que sua prática não se limita à produção de livros com capas de papelão pintadas à mão, mas que se alinha à questões sociais, de sustentabilidade, incentivo à leitura e à diversidade literária e de vozes, de uma prática de produção coletiva e uma comercialização a preços populares ampliando as possibilidades de aquisição deste artefato que ainda é elitista, ou seja, uma disputa de campo.

Seus livros não reproduzem uma estética da miséria nem tampouco são produtos da crise, como são frequentemente associados. Eloísa Cartonera é um local para se trabalhar e estar em conjunto. "As pessoas juntam-se para estarem umas com as outras, para aprender umas com as outras, para ganhar a vida. Como valor acrescido, sempre é referido o prazer de produzir e pintar livros e de conhecer pessoas novas, frequentemente de culturas distantes" (Bértholo, 2009, s/p).

Terzaghi (2018) divide a prática cartonera em três categorias centrais: pedagógicos, políticos e poéticos. A categoria poética pode ser compreendida no sentido de poiesis como ato criativo que ocorre a partir do encontro e da troca de saberes entre os participantes. 
"Aqui as formas do poético não se separam do estético, mas constituem um regime que se entende como modos de se mostrar, associados a modos de abordar o ato criativo, do qual não se espera que assuma uma forma única" (p. 46). A autora relaciona a dimensão política a sua raiz etimológica que se refere a algo que acontece com grupos sociais na polis. Busca utilizar o termo em um sentido mais amplo e "referenciar uma perspectiva de algo que é reconhecido como o público, o lugar do cidadão na comunidade, o comum e não estritamente aquilo que está associado ao lugar de governo ou ao lugar dos governantes" (p. 47). Já a categoria pedagógica da prática cartonera implica em estar presente e atento àquela prática e aos encontros que ali ocorrem. "Assim, o encontro atravessado por diferenças e afetos, como experiência dotada de sentido, faz parte do tema aqui em jogo. Encontrar o outro é superar uma forma de relação instrumental em prol de uma reciprocidade, de um ser e fazer com o outro" (idem, p. 49).

\section{Muito mais que livros, o fazer cartonero}

Apresentadas as condições de constituição do universo cartonero e como o trabalho do catador se insere no centro de produção deste universo, partimos para a primeira formação, Eloísa Cartonera. Fundada em 2003 pelo escritor Washington Cucurto, pseudônimo de Santiago Veja, e pelos artistas plásticos Javier Barilaro e Fernanda Laguna. A oficina que hoje recebe o nome de Cooperativa de Trabajo Gráfico Editorial y de Reciclado Eloísa Cartonera Ltda. fica localizada no bairro do Boca, próximo ao estádio do Boca Juniors. O coletivo funciona em uma oficina onde, inicialmente, se vendia não só os livros, mas também verduras e legumes. Assim, traz uma nova proposta de fazer e comercializar o livro.

O nome Eloísa Cartonera faz referência a um amor de verão não correspondido entre um de seus fundadores por uma jovem boliviana. Ao dar o nome da jovem para o projeto da editora, Barilaro acreditou que a homenagem renderia frutos e que poderia conquistar o coração da moça, mas o resultado foi o oposto.

É muito comum que as editoras cartoneras recebam nomes de mulheres ou substantivos femininos como vemos na própria Eloísa Cartonera e em outros coletivos como Dulcinéia Catadora (São Paulo, Brasil), Sarita Cartonera (Lima, Peru), Eva Cartonera (Barreiro, Portugal), Yiyi Jambo Cartonera (Pedro Juan Caballero, Paraguai), Animita Cartonera (Santiago, Chile), Mariposa Cartonera (Recife, Brasil), Olga Cartonera (Chile), entre tantas outras. A ausência de hierarquia e o não comprometimento com definições e rotulações são dois aspectos característicos das cartoneras e que estão relacionados ao feminino (Krauss, 2015).

As editoras cartoneras possuem um modo de organização e produção não capitalista. Formadas por uma multiplicidade de atores não existe uma hierarquia entre eles, todos os integrantes do coletivo conhecem todos os processos de fabricação de livros, desde a impressão, confecção das capas até participação em palestras e oficinas de livro (Braga, 2014). O protagonismo é dos catadores de material reciclado, responsáveis pela retirada desse material (papelão) do lixo e sua transformação em livro. 
Vilhena (2016) compara o esquema de trabalho de realizado pelo coletivo ao de mutirão e busca na origem da palavra, motyrõ, em tupi , o significado de trabalho em comum que, originalmente, estava associado à colheita e à construção de casas populares. De acordo com o Wikipedia, "mutirão é, no Brasil, uma mobilização coletiva para lograr um fim, baseando-se na ajuda mútua prestada gratuitamente". Entretanto, a autora destaca aqui uma diferença importante:

no mutirão não existiria uma mercadoria final, fato do qual a produção cartonera se afasta: se a produção cartonera é realizada nos moldes de um mutirão, é visando um produto final que, na sequência, vai ser tomado como uma mercadoria. Com relação à posse dos meios de produção, estes são propriedade dos próprios componentes da cooperativa, de modo que não existe reprodução do esquema patrão/trabalhador-empregado ou chefe/demais funcionários; como consequência, tampouco existe o sobretrabalho que irá redundar na mais-valia da qual o patrão se beneficia (Vilhena, 2016, p. 49).

Outro ponto importante a ser destacado é o caráter de sustentabilidade que envolve o universo cartonero. É mais fácil de perceber pela reutilização do papelão que, após descartado, volta a ser reinserido no ciclo produtivo. Entretanto, não é apenas o papelão que se transforma, do lixo ao livro, mas sobretudo a relação do catador com seu trabalho e com a cidade.

Podemos observar como metaforicamente existe aqui uma declaração bastante poderosa, acerca da forma como escolhemos desperdiçarmos ou reintroduzir tantos os nossos excedentes materiais, como humanos. $E$ isso é pertinente quando se fala da parte material, o cartão, mas terrivelmente polêmico e desestabilizante quando se dirige à parte humana, os cartoneros (Bértholo, 2009, s/p).

O papelão utilizado para confeccionar as capas dos livros é comprado diretamente dos catadores ou das cooperativas por um valor acima do oferecido pelo mercado. As capas são pintadas à mão, de modo que não existe um livro igual ao outro. Muitas vezes, a história daquele material que já teve uma outra finalidade, como partes de logotipos, inscrições ou nome do produto que embalava, permanece preservada pelas camadas de tinta de recebe. Esses livros mantém uma certa aura pelo seu caráter de unicidade.

Após o surgimento da Eloísa Cartonera, na Argentina, o número de coletivos cartoneros se multiplicou pelo mundo, sobretudo por toda América Latina, inclusive no Brasil, que já somava 26 editoras cartoneras no ano de 2016. O número de cartoneras ativas no ano de 2021 é impreciso, mas alguns praticantes chegam a falar de, aproximadamente, 300 cartoneras espalhadas pelo mundo. Eloísa Cartonera, nesse sentido, pode ser considerada a mãe das cartoneras e a rápida disseminação dessa prática pelo mundo demonstra o potencial polinizador desses agentes. Assim como o trabalho indispensável da abelha não é a produção de mel e cera, como destaca Moulier-Boutang (2012), mas a polinização responsável pela reprodução da vida, o trabalho essencial das cartoneras também não é a produção do livro, mas de outras formas de viver e produzir.

Essa multiplicidade de cartoneras traz algumas diferenciações entre cada projeto. Pimentel (2021) percebe três grandes grupos distintos, a saber, os projetos individuais, os coletivos cartoneros e as cartoneras universitárias. Apesar das particularidades de cada uma delas, o que une o universo cartonero é a prática contra a lógica capitalista colonialista, uma prática baseada na solidariedade e no compartilhamento. 
As teias cartoneras têm como princípio fundamental o "cooperativismo, a autogestão e trabalhar pelo bem comum", descrição presente no site da cartonera argentina. Rompendo com a hierarquia e com a lógica de produção capitalista, as cartoneras habitam as margens do sistema e criam outras formas de habitar o mundo. Muito mais que livros, as cartoneras vendem outros valores e possibilidades de estar. Como bem destaca Bértholo (2009), as cartoneras

oferecem uma oportunidade para questionar a sua potente indústria editorial, e as armadilhas da sua cultura profundamente capitalista. Para as classes mais baixas, oferecem a perspectiva de um caminho para aqueles que se sentem impotentes perante a falta generalizada de emprego. Para todos os outros, oferecem imagens maravilhosamente românticas de outras formas pelas quais o mundo poderia funcionar. Oferecem acesso e visibilidade a um fenômeno que não pode passar omisso, a realidade destes milhares de pessoas que vivem diariamente dos detritos e subprodutos das sociedades que os acolhem ( $\mathrm{s} / \mathrm{p})$.

A prática cartonera é uma prática insurgente que luta por processos de existência de novos modos para além do modelo colonialista capitalista, uma prática de rexistência. O termo rexistência foi proposto por Viveiros de Castro em relação às comunidades indígenas para evidenciar $\mathrm{o}$ ato de resistir que reinventa outras maneiras de existir. Assim, a prática de rexistência das cartoneras se dá no pensar e agir coletivamente criando outra forma de vida que confronta a dinâmica e a lógica imposta pelo modelo hegemônico capitalista colonial, sobretudo para essas comunidades que são cotidianamente marginalizadas e silenciadas.

\section{Dulcinéia Catadora e a produção do comum}

Em 2006, Eloísa Cartonera foi convidada a participar da $27^{\mathrm{a}}$ Bienal de São Paulo que tinha o tema "como viver junto", com a curadoria de Lisette Lagnado. O objetivo do coletivo na Bienal não era apresentar ou expor seus livros prontos, mas confeccioná-los durante o período da Bienal através de oficinas de produção de livro cartonero dentro do pavilhão no Ibirapuera. Em entrevista ao site Fórum Permanente, Javier Barilaro afirma que a ideia era iniciar um projeto aqui no Brasil. "A ideia não é a de autoria nem a de empresa que vende, mas a de buscar um intercâmbio humanístico, em que todos aprendam de tudo" (Barilaro, s/d).

Para viabilizar a execução das oficinas na Bienal, era necessário reunir uma grande quantidade de papelão para ser utilizado durante todo o período do evento (Vilhena, 2016). Para isso, Eloísa Cartonera convidou a artista plástica Lúcia Rosa, que já trabalhava com papelão e já havia realizado trabalhos colaborativos com integrantes do coletivo, para auxiliar na aquisição de material entre as cooperativas de São Paulo. Graça (2016) comenta a resistência que Lúcia Rosa encontrou ao convidar os catadores de material reciclável a participar da Bienal, um evento de arte.

Foi durante as buscas por cooperativas de catadores de materiais recicláveis que aceitassem participar da Bienal que Lúcia Rosa conheceu Dulcinéia, catadora que se disponibilizou em ajudar na busca por catadores interessados. Ao final da Bienal, que durou de outubro a dezembro de 2006, o grupo decidiu dar continuidade ao trabalho e criaram sua própria cartonera, o coletivo Dulcinéia Catadora, a primeira cartonera do Brasil (Graça, 2016). 
Como a maioria das cartoneras da América Latina, Dulcinéia Catadora também foi batizada com o nome de uma mulher, Maria Dulcinéia da Silva Santos, uma das catadoras da cooperativa Coopamare. Dulcinéia também representa o amor no romance Dom Quixote, de Miguel de Cervantes, a personagem representa a musa inspiradora e o amor ideal nunca atingido.

Assim como Eloísa Cartonera, Dulcinéia Catadora também coloca o catador de papelão no centro do sistema de produção, não só no nome do coletivo como também em sua prática, indicando a potência desses coletivos. "E, o que faz o 'cartonero' é justamente trabalhar na fronteira daquilo que serve daquilo que não serve, é um sujeito social que habita e trabalha no entremeio" (Krauss, 2015).

Além do envolvimento com a produção do livro, o coletivo Dulcinéia Catadora promove uma série de oficinas no Brasil e no mundo a fim de incentivar a formação de novos núcleos cartoneros, capacitando pessoas interessadas no trabalho, além de gerar renda para o coletivo e para as catadoras.

O Dulcinéia Catadora produz livros feitos artesanalmente com o objetivo primeiro de gerar renda para as catadoras que participam do coletivo. O livro, como instrumento de veiculação de obras literárias, é decorrência desse processo artístico. Com diagramações simples, em geral as edições são feitas com cópias, e não impressas em gráficas; fazemos tiragens pequenas, de cinquenta, cem livretos e refazemos conforme chegam os pedidos (Rosa, 2016).

Os livros são produzidos a partir de um material que seria descartado, o papelão, que volta a ser reintegrado no ciclo produtivo. O próprio site Dulcinéia Catadora afirma que "essa é uma forma original de confeccionar livros como um instrumento de resistência e crítica às práticas tradicionais, comerciais, nas mãos do mercado editorial".

Lúcia Rosa (2021) comenta que ao retirar o papelão do circuito do descarte, ele passa a ser utilizado de uma forma criativa e instaura um outro circuito mediado pelos livros cartoneros. $\mathrm{O}$ livro é o que possibilita essas catadoras de transpassarem os muros da cooperativa e ocuparem lugares na cidade. À medida que essas catadoras e esse trabalho do livro com capa de papelão ocupa esses lugares da cidade, se instaura a possibilidade de convívio, de diálogo desse segmento, que é invisível, com outros segmentos sociais. O livro com capa de papelão faz esse papel de ponte, promove diálogo.

Os escritores são convidados casualmente a colaborar com o coletivo, seja por e-mail ou em encontros e feiras independentes. Tudo acontece verbalmente, sem nenhum tipo de contrato. Escritores já renomados no mercado e aqueles que ainda não tiveram um espaço de expressão, todos têm voz e vez dentro do coletivo. "Nós não queremos deter direitos de ninguém. (...) Eu costumo dizer que direitos autorias, produção, catálogo, não fazem parte do nosso universo. É um coletivo de arte" (Rosa, 2015). Portanto, os livros não fazem parte de um negócio que visa o lucro. Nem mesmo a relação com os escritores é comercial. "Baseia-se na troca de experiências e vivências, na cumplicidade de uma postura de resistência, no trabalho conjunto, no processo", afirma Lúcia.

O papel do coletivo é de resistir, de traçar caminhos paralelos ao mercado editorial, de cavar oportunidades, tornar acessível o trabalho de escritores novos e buscar novas propostas literárias, 
textos experimentais. (...) Não visar ao lucro é a chave para a nossa liberdade de escolher autores sem ter a garantia de que seus livros vendam bem. (...) E mais, estar livre dos canais de distribuição, das negociatas com livrarias, das estratégias de marketing significa pensar na qualidade do texto literário, dar vez aos escritores que estão se firmando. (...) A liberdade é nosso diferencial, em relação às editoras estabelecidas (Rosa, 2016).

Por isso os livros não possuem ISBN, ficha catalográfica nem são comercializados em livrarias, mecanismos e espaços utilizados pelo mercado hegemônico. Tais escolhas reforçam o caráter contestatório dos livros que eles prescindem de exigências que vem de um mercado editorial formal. Lúcia Rosa considera a prática cartonera uma prática revolucionária

no sentido de que a presença desses livros em lugares culturais, bibliotecas, galerias de arte, significou o reconhecimento de uma linguagem. Feito com um material de descarte, por catadores. Muda a concepção ou as exigências das editoras de livros que vendam ou que sejam obras qualificadíssimas de autores respeitáveis. Um livro e um objeto que acolhe a voz de escritores, de alguém que escreve e tem direito a se expressar (Rosa, 2021).

O grupo formado inicialmente já se reconfigurou e, atualmente, o coletivo é formado por quatro mulheres, as catadoras da CooperGlicério: Maria Aparecida Dias da Costa (presidenta da cooperativa), Eminéia Silva Santos, Andreia Ribeiro Emboava (secretária e administradora da cooperativa) e Lúcia Rosa (Graça, 2016), além das parcerias que vão surgindo na edição de cada título. "É um trabalho coletivo, do convívio nasce a diferença, o lidar com o outro, com pensamentos diferentes, lidar com os antagonismos de segmentos sociais muito diferentes" (Rosa, 2021). É nesse encontro da diferença que está a riqueza e a potência do universo cartonero.

Atualmente, Dulcinéia Catadora funciona em uma pequena sala dentro da cooperativa de catadores de materiais recicláveis CooperGlicério, na Baixada do Glicério, localizada entre os distritos da Sé e da Liberdade, espaço cedido pela prefeitura que pude conhecer em uma visita ao coletivo em março de 2020. A Cooperativa foi fundada em 2006 pelos próprios catadores que trabalhavam puxando suas carroças pela cidade de São Paulo a partir de um projeto sócioeducativo desenvolvido pela Recifran, Serviço Franciscano de Apoio à Reciclagem.

A Cooperativa foi criada com a finalidade de evitar as desavenças com a prefeitura pela utilização daquele território e tinha o objetivo de melhorar as condições de trabalho e potencializar a comercialização de materiais, buscando criar relações de negócio com compradores, empresas, ongs e poder público. De acordo com o Movimento Nacional de Catadores de Materiais Recicláveis (MNCR), o grupo de catadores se encontrava em situação de risco, após passarem por um período em que tiveram seus direitos violados por funcionários da Prefeitura e por empresas de compra de recicláveis. $O$ fato foi denunciado às autoridades como promoção de trabalho escravo e, a partir de então, os catadores decidiram criar a associação para gerir o espaço.

Em 2017, a CooperGlicério sofreu uma ameaça de despejo pelo governo João Dória que alegava invasão de área pública. Porém, a cooperativa é parte da política pública municipal de inclusão social de catadores de materiais recicláveis da região da Baixada do Glicério e está 
amparada por decreto municipal que dispõe sobre a cessão de uso das áreas localizadas nos baixos de pontes e viadutos municipais.

Localizada embaixo do viaduto do Glicério, um dos maiores anéis rodoviários da cidade de São Paulo, Dulcinéia Catadora utiliza o espaço da CooperGlicério para produzir seus livros numa lógica anticapitalista buscando ampliar o acesso de escritores e de leitores no campo editorial. Na contramão da política neoliberal e das subordinações impostas pelo sistema capitalista à mercadoria, vinculamos a ideia do comum aos

princípios de autonomia, democracia direta, horizontalidade e autogestão, a organização em redes digitais, a rejeição à tutela do Estado e a ocupação de espaços públicos são características que conectam esses novos movimentos a mobilizações variadas (Dellenbaugh et al., 2015; Kip, 2015). Ao evocar um porvir não capitalista para além da antinomia moderna Estado versus mercado, propriedade pública versus propriedade privada, a noção de comum aproxima-se de um campo de práticas mais autônomas e coletivas de produção e reprodução social (TONUCCI FILHO, 2020, p. 372).

A prática cartonera pode ser compreendida como uma constituição do comum pela sua prática coletiva, pelo compartilhamento e suas relações que criam uma nova forma de produzir e estar no mundo, um fazer-comum. O fazer cartonero unindo a pobreza - não no sentido da falta, mas da possibilidade, nas formas de vida, de linguagens, e produtividade - e o amor, que oferece o poder de se tornar definido pela diferença, tal como afirmam Hardt \& Negri (2016), reúne os elementos essenciais na produção do comum.

\section{Agradecimento}

O presente trabalho foi realizado com apoio da Coordenação de Aperfeiçoamento de Pessoal de Nível Superior - Brasil (CAPES) - Código de Financiamento 001.

\section{Referências}

Barilaro, J. (s/d). Projeto Eloísa Cartonera: Entrevista com Javier Barilaro. Forum Permanente. Disponível em: http://www.forumpermanente.org/rede/numero/revNumeroOito/oitoentrevistacartonera. Acesso em 22 fev. 2021.

Bértholo, J. (2009). Muito mais do que livros: o fenómeno editorial <cartonero> pela América Latina. Disponível em: < https://www.magazineim.com/home/index.php/unique-books-eloisacartonera/?lang=pt> Acesso em 18 mar 2021.

Braga, A. (2014). A. Redes de comunicação no coletivo Dulcineia Catadora e o arte ativismo de convívio. Dissertação (Mestrado). Pontifícia Universidade Católica de São Paulo. São Paulo.

Graça, L. A. (2016). Margens silenciadas: arte colaborativa e a busca por protagonismo. Dissertação (Mestrado). Universidade Federal do Rio Grande do Sul, Programa de PósGraduação em Artes Visuais. Porto Alegre.

Hardt, M. \& Negri, A. (2016). Bem-estar comum. Rio de Janeiro: Record. 
Krauss, F. (2015). As cartoneras no entremeio: uma entrevista com Flavia Krauss. Disponível em: https://malhafinacartonera.wordpress.com/2015/11/04/as-cartoneras-no-entremeioentrevista-com-flavia-krauss/. Acesso em 20 fev. 2021.

MNCR. Movimento Nacional dos Catadores de Materiais Recicláveis. Disponível em: http://www.mncr.org.br/noticias/blog-sudeste/organizacoes-de-catadores-do-centro-de-saopaulo-podem-ser-despejadas-a-qualquer-momento. Acesso em 06 abr 2021.

Moulier-Boutang, Y. (2012). Revolução 2.0, comum e polinização. In: COCO, G.; ALBAGLI, S. Revolução 2.0: e a crise do capitalismo global. Rio de Janeiro, Garamond.

Pimentel, A. (2021). Editoras cartoneras e a literatura fora do cânone: um olhar crítico para as margens do mundo editorial. Estud. Lit. bras. Contemp., Brasília, n.62, e622, 2021.

Rosa, L. (2015). O livro pelo coletivo Dulcinéia Catadora. Vídeo. (13 April 2015). Disponível em: https://www.youtube.com/watch?v=KJkuOZboLHQ Acesso em 19 mar 2021.

Rosa, L. (2016). Entrevista com Lúcia Rosa, Coletivo Dulcinéia Catadora. Disponível em: https://cidadeverde.com/janelasemrotacao/75532/entrevista-com-lucia-rosa-coletivodulcineia-catadora Acesso em 20 mar 2021.

Rosa, L. (2021). Diálogos: cartoneirismo em tempos sombrios. Produtora Nós Pós. Disponível em: https://www.youtube.com/watch?v=gPqMI_JSHC0\&t=6s Acesso em 19 mar 2021.

Tonucci Filho, J. B. (2020). Do direito à cidade ao comum urbano: contribuições para uma abordagem lefebvriana. Rev. Direito e Práx., Rio de Janeiro, Vol. 11, N. 01, 2020, pp. $370-$ 404.

Vieira, E. R. P., \& Thompson, A. (2012). Neoliberalism and its eff ects on labour: El Tren Blanco and the Argentinian cartoneros. Ipotesi, Juiz de Fora, v.16, n.1, p. 65-78, jan./jun. 2012.

Vilhena, F. (2016). O acontecimento Eloísa Cartonera: memória e identificação. Tese (Doutorado). Faculdade de Filosofia da Universidade de São Paulo, São Paulo.

\section{Sobre a autora}

Carolina Noury, Dra., Esdi/UERJ, Brasil <carolinanoury@gmail.com> 